Nussbaum M. C., (2002) Patriotism and Cosmopolitanism. In: Nussbaum M. C. For love of country? Massachusetts, Beacon Press. 153 p. Pp. 3-17.

Pavkovié, A. (2007) Killing for One's Country. In: Patriotism. Philosophical and Political Perspectives. Primoratz, I., Pavkovié A. (eds.). Hampshire, Ashgate. 241 p. Pp. 219-234.

Shaar, J. H. (2002) The Case for Covenanted Patriotism. In: Patriotism. Primoratz I. (ed.). Amherst, Humanity Books. 298 p. Pp. 233-257.

Taylor Ch. (2002) Why Democracy needs Patriotism. In: Nussbaum M. C. For love of country? Massachusetts, Beacon Press. 153 p. Pp. 119-121.

Viroli, M. (1995) For Love of Country. An essay on patriotism and nationalism. Oxford, Clarendon Press. 206 p.

Wallerstein I. (2002) Neither Patriotism Nor Cosmopolitanism. Nussbaum M. C. For love of country? Massachusetts, Beacon Press. 153 p. Pp. 122-124.

Submission date: 20.03.2018.

Павлов Александр Владимирович - кандидат юридических наук, ведущий научный сотрудник, заведующий сектором социальной философии Института философии РАН. Адрес: 109240, Россия, г. Москва, ул. Гончарная, д. 12, стр. 1. Тел.: +7 (495) 697-98-93. Эл. адрес: alepavlov@yandex.ru

Pavlov Aleksandr Vladimirovich, Candidate of Law, Leading Research Fellow, Head, Sector of Social Philosophy, RAS Institute of Philosophy. Postal address: 12, Bldg. 1, Goncharnaya St., Moscow, Russian Federation, 109240.Tel.: 7 (495) 697-98-93.E-mail: ale-pavlov@yandex.ru

DOI: $10.17805 /$ zpu.2018.2.9

\title{
Концептуальный анализ экзистенциально-феноменологической традиции: основания и перспективы
}

\author{
О. А. ВЛАСОВА, А. А. ЛЬВОВ \\ САНКТ-ПЕТЕРБУРГСКИЙ ГОСУДАРСТВЕННЫЙ УНИВЕРСИТЕТ
}

Статья предлагает новую интерпретацию экзистенциально-феноменологической традиции как единого проблемного и прикладного поля на границе философии, психиатрии, психотерапии и психологии. В качестве основания исследования экзистенциально-феноменологической традиции предлагается использовать концептуальный анализ. Он позволяет выделить фундаментальные концепты традиции, сохраняющиеся при переходе от теории к практике или трансформирующиеся с целью реализации задач терапии в промежуточные понятия.

Воссоздается история развития экзистенциально-феноменологической традиции как смена четырех парадигм: общегуманитарной, экзистенциально-феноменологической, социально-критической, междисциплинарной парадигмы философии психиатрии. Показывается фундаментальное значение экзистенциально-феноменологической традиции в свете этого процесса.

Выделяются ряды концептов экзистенциально-феноменологической философии, психологии, психиатрии и психотерапии: онтологические, методологические, антропологические, коммуникативные, проясняется статус каждой концептуальной группы. Указывается, что концептуальным ядром традиции являются методологические концепты (феноме- 
нологические, герменевтические, проблемно-предметные), и они наиболее устойчивы при переходе от философского к прикладному полю. Онтологические и антропологические концепты формируют теорию и показывают специфику авторских проектов. Они могут быть как заимствованными из философии понятиями, так и авторскими метаонтическими концептами, специфичными для прикладного поля экзистенциально-феноменологической традиции и образованными на пересечении философской онтологии и психиатрической, психологической, психотерапевтической антропологии. Коммуникативные концепты часто связываются с другими типами концептов и наиболее эклектичны, при этом описывают реальность как врача, так и пациента.

Показываются перспективы предложенной модели интерпретации, в рамках которой лучше проясняются основания и линии методологической и теоретической преемственности в рамках различных областей традиции.

Ключевые слова: экзистенциально-феноменологическая традиция; феноменология; экзистенциальная философия; концептуальный анализ

\section{ВВЕАЕНИЕ}

$\mathrm{B}$ настоящее время в России происходит активное обращение к проблематике, являющейся результатом взаимодействия, с одной стороны, пространства философии, а с другой - пространства психиатрии, психотерапии и психологического консультирования. При этом диалог этих парадигм происходит преимущественно в рамках экзистенциально-феноменологической традиции.

Подтверждение интереса к экзистенциально-феноменологической традиции можно обнаружить как в теоретических, так и в практических областях. Этот рост интереса наблюдается по монографиям, статьям, диссертационным исследованиям, переводам. В последние десятилетия активно внедряются в практику методы гуманистической психотерапии и психологии, освоение которых немыслимо без обращения к экзистенциально-феноменологической философии, ее концептуальному содержанию и методологическим основаниям. Заинтересованность теоретиков и практиков отражается и на уровне академического и психотерапевтического сообщества. Проводятся конференции и семинары, которые собирают на одной площадке философов, психиатров, психотерапевтов и практикующих психологов.

Исключительно теоретические ходы, концепты и методы феноменологии и әкзистенциальной философии были трансформированы в прикладных науках о человеке психологии и психиатрии. Их развитие было подчинено практическим задачам - работе с психически больными пациентами и людьми с психологическими проблемами. При этом экзистенциально-феноменологическая психиатрия формируется при прямом влиянии феноменологии и экзистенциальной философии и независимо от психологии, гуманистическая психология же продолжает как философские, так и психиатрические идеи.

Почему трансформировались основные концепты и методы на пути от экзистенциально-феноменологической философии к психиатрии и психологии, каковы движущие факторы этих трансформаций, можно ли говорить о перестраивании концептуальных связей или же мы просто видим развитие уже имеющихся; как повлияла практическая направленность психологии и психиатрии на эти трансформации - это насущные вопросы анализируются в настоящей статье.

\section{ПУТИ ТРАНСФОРМАЦИЙ}

Историю взаимодействия философского и психиатрического дискурсов можно представить в качестве последовательно сменяющих друг друга четырех этапов 
(см.: Власова, 2010: 16, 39-40; Власова, 2014: 16). Прежде всего это обозначившаяся в работах 3. Фрейда, Ю. Блейлера и Х. Прицхорна общегуманитарная парадигма, господствовавшая в исследовательском пространстве до 1930-х годов. Аалее, в период 1930-1960-х годов, с появлением трудов $\Lambda$. Бинсвангера, Э. Минковски, Э. Штрауса, В. Э. фон Гебзаттеля, М. Босса, а также работ М. Хайдеггера на смену ей приходит экзистенщиально-феноменологическая парадигма. В 1960-е годы возникает и активно развивается вплоть до конца 1980-х годов социально-критическая парадигма, которую в литературе нередко называют также антипсихиатрией. Среди ее представителей можно назвать М. Фуко, Р. Аэйнга, А. Купера, Т. Саса и И. Гофмана. Наконец, с 1990-х годов плодотворное, взаимно обогащающее сотрудничество психиатрии и философии позволило сформировать междисциплинарную область философии психиатрии (которую исследователи нередко относят к области прикладной, или практической, философии) (см.: Fulford, 1996: 1).

Экзистенциально-феноменологической традиции принадлежит особое место в указанном процессе: она одновременно и собрала общегуманитарные наработки предшественников, и обеспечила весомый задел для последователей. Именно она оказалась наиболее популярной и продуктивной в среде исследователей.

Основание продуктивности экзистенциально-феноменологической традиции для прикладных областей - психологии, психиатрии и психотерапии - возможность формирования так называемой метаонтики. Впервые о существовании подобного междискурсивного поля заговорил Аж. Нидлман в своем исследовании идей Аюдвига Бинсвангера (Нидлман, 1999). По Нидлману, метаонтика представляется чем-то лежащим на пересечении философской онтологии и данной конкретной психиатрической антропологии, при этом изначально она структурируется как прикладное поле. Метаонтическое пространство, таким образом, мыслится как оригинальный ансамбль онтологии и антропологии, в рамках которого психическое заболевание предстает в качестве своеобразного способа бытия, экзистенциального модуса.

Надо признать, что с самого начала вхождения экзистенциально-феноменологической традиции в прикладное поле, т. е. во время рецепции феноменологии психиатрией, идеи философов не были восприняты в оригинальном ключе. Они были сциентизированы и антропологизированы, и подобное восприятие сохраняется и до сих пор, а философы пытаются пояснить, насколько такая интерпретация неадекватна исходному замыслу. Мы можем увидеть это, например, в идеях А. Захави - в его специфическом восприятии трансцендентальной феноменологии Гуссерля. В недавно опубликованной на русском языке статье он подчеркивает: «Главная цель феноменологии не заключается ни в скрупулезном описании опыта, ни в эйдетическом анализе различных регионов бытия. <...> Гуссерля интересуют отношения между интенциональностью восприятия и научной рациональностью.... Более того, известно, что Гуссерль критиковал чисто описательную феноменологию, уподобляя ее книжкам с картинками» (Захави, 2017: 152). Однако описательная феноменология и легла в основание прикладной экзистенциально-феноменологической традиции.

Метаонтика предполагает наличие своеобразного, адаптированного к предмету изучения психиатрии, метода, который в основных своих чертах заимствуется из философии. Определяющей методологической установкой оказывается здесь феноменологическая редукиия, поскольку именно она позволяет раскрыть патологический опыт во всем его существе - за безликим нагромождением симптомов и синдромов обнаружить определенный способ существования, а в личине дезориентированного 
и фрустрированного пациента суметь разглядеть неповторимое человеческое лицо. «Болезнь в первую очередь является способом человеческого бытия...» - подчеркивает В. Э. фон Гебзаттель (Gebsattel, 1959: 194-195, 208). Редукция вместе с тем подкрепляется и методами понимающей психологии (принципы которой разработал К. Ясперс), ведь именно понимание дает возможность проникнуть в существование больного, вскрыть его уникальный опыт, описать его и сохранить. Так, Ясперс указывает, что «мы должны использовать термин “понимание” (Verstehen) только в применении к пониманию событий психической жизни “изнутри”» (Ясперс, 1997: 20). И феноменологическая редукция, и понимающая психология устремляются к самому пациенту.

Однако практика немыслима без исследования, и здесь на сцену выходит феноменологически-структурный анализ. Он позволяет воссоздать целостную структуру расстройства психики, фиксируя отдельные явления патологического опыта, а также выявляя существующие между ними связи, о чем в одной из своих работ красноречиво свидетельствует Э. Минковски (творчески отталкиваясь от идей А. Бергсона): «Когда я сижу напротив своего больного, в какой-то момент, иногда в результате единственной фразы, у меня вдруг самым живым образом возникает интуитивное понимание общей взаимосвязи, а также того, что я имею дело с базисным нарушением, на котором основываются все остальные расстройства, которые проявляются вовне и, следовательно, могут стать объектом описания» (Minkowski, 1948: 145). Завершает эту своеобразную неоднородную методологию экзистенииальная герменевтика, с помощью которой оказывается возможным увязать структурные особенности патологического опыта конкретного пациента с онтологической рефлексией и интерпретировать его в контексте бытия-в-мире (Binswanger, 1963; Бинсвагер, 2001).

Развитие экзистенциально-феноменологического направления сыграло важнейшую роль в обозначившемся в начале XX в. гуманистическом повороте. Это направление можно считать знаковым для европейской континентальной традиции, поскольку в Америке, например, экзистенциально-феноменологическая психиатрия как задуманный ее основателями проект не получила широкого распространения, хотя для этого и сформировались все необходимые предпосылки. Вместо нее появилась и нашла повсеместное признание экзистенииальная, или гуманистическая, психология. В основу ее были положены принципы европейского экзистенциального анализа и школы гештальтпсихологии. Однако все эти направления использовали концепты феноменологии и экзистенциальной философии, добавив к ним свои, новые психологические и психотерапевтические понятия.

\section{КОНЦЕПТУААЬНЫЙ АНААИЗ: СУТЬ ПРОБАЕМЫ}

Экзистенциально-феноменологическая традиция успешно развивается, она дала ответвления в виде очень популярных направлений. В чем, собственно, состоит проблема с прояснением ее концептуального аппарата?

Проблемная ситуация видна по литературе. В мире существует значительное количество словарей, посвященных терминологии Гуссерля (Moran, 2012; Drummond, 2008) и Хайдеггера (Dahlstrom, 2013), Сартра (Сох, 2008) и Мерло-Понти (Landes, 2013), однако всего один - экзистенциально-феноменологической психотерапии, и он показывает, что анализ понятий здесь - не такая простая вещь.

«Словарь экзистенциальной психотерапии и консультирования» под редакцией известных специалистов в этой области Эмми ван Аорцен и Раймонда Кенворда вышел 
в 2005 г. в издательстве «Sage Publications» (Deurzen, Kenward, 2005). 228 страниц достаточный объем для того, чтобы отразить всю сложность понятийных коллизий и жизненных траекторий. Однако в предисловии авторы-составители признаются, что на данном этапе провести глубокое исследование невозможно, что были вынуждены многое отсеять, и предлагают читателю присылать свои предложения для второго издания.

Ван Аорцен и Кенворд включают в словарь три типа терминологии: персоналии, экзистенциальную (философскую) терминологию и связанные понятия, которых касались экзистенциальные философы, но которые не были выработаны ими самими. При этом они делают упор на философию, а не на прикладные пространства психотерапии и консультирования. «Идеи, представленные в работе, скорее, философские, чем психологические, поскольку читателю, впервые обратившемуся к экзистенциальной психотерапии, может быть интересно, какое отношение философия вообще имеет к психотерапии. Аля такого читателя может быть полезным обращение к составляющим философии и экзистенциальной психотерапии», - признаются они (там же: 3 ). Авторы делают выбор в пользу простого языка, цитируют экзистенциальных философов и в конце каждой словарной статьи приводят возможные связанные понятия, которые содержатся в книге.

Что показывает опыт этого единственного в своем роде издания? Словарь ван Аорцен и Кенвуда - это словарь известных понятий, тех, к которым часто обращаются психотерапевты и психологи. Хайдеггерово «бытие-в-мире», Сартрово «в-себе» и «для-себя», Гуссерлевы «редукция», «интенциональность», Ясперсовы «пограничные ситуации», «болезнь-к-смерти» Кьеркегора и пр. Все они даны с опорой на тексты самих философов, часто с их цитированием. Он показывает хорошую выборку терминологии и персоналий, которые оказались полезны прикладникам, т. е. сам этот словарь вдобавок к его непосредственной ценности показывает, как восприняли экзистенциальную традицию психотерапевты и психологи, что оказалось у них востребованным.

Вместе с тем словарь оказывается словарем терминов (в общем-то, авторы и ставят такую задачу), но не понятий-концептов, которые являются образующими для теорий. Эта работа гораздо сложнее, она предполагает долгое, вдумчивое исследование на границе философии, психологии, психиатрии, психотерапии. Она связана с пониманием оснований процесса сближения, который произошел. Сложность подобного исследования и составления подобного словаря связана с тем, что в настоящее время пока еще отсутствует достаточная дистанция по отношению к происходящему. Экзистенциальная психотерапия и психология бурно развиваются и сохраняют популярность, специалисты активно используют достижения экзистенциально-феноменологической традиции, но концептуальная рефлексия сразу на трех уровнях затруднена. Как она должна выглядеть? Что, собственно, представляет концептуальный анализ экзистенциально-феноменологической традиции, который, как мы утверждаем, ей насущно необходим?

Формирование метаонтики в рамках экзистенциально-феноменологической психиатрии приводит не просто к оформлению некоего проблемного поля: в данном случае таковым оказывается проблема патологического опыта со смежными вопросами и соответствующими методами интерпретации. Метаонтика имеет самостоятельную философскую ценность как рефлексия о человеке, хотя и о человеке, страдающем психическим расстройством. Теория метаонтики может быть разбита на вполне тра- 
диционные философские поля - онтологию, методологию, антропологию, в меньшей степени в ней выражены социально-философская и этическая составляющие, зато добавляется составляющая практически ориентированная.

Концепты экзистенциально-феноменологической психиатрии - это не просто слова, термины. Они содержат теоретическое ядро и методологические отсылки. Они показывают, о чем речь и для чего мы об этом говорим. Эти понятия заимствуются из экзистенциально-феноменологической философии в непереработанном виде (что редко и относится только к самым основополагающим понятиям) или трансформируются и приспосабливаются для нужд практики.

Ядро своеобразия экзистенциально-феноменологической психиатрии - методологические концепты, которые наиболее устойчивы при переходе от философской феноменологии и экзистенциальной философии к психиатрии, психотерапии и психологии. Среди них выделяются феноменологические - перешедшие из феноменологии и экзистенциальной философии с ненезначительными изменениями ( феноменология», «феноменологическая установка», «феноменологическая редукция»и пр.); герменевтические - составляющие основу практик и направленные на работу с человеком и разработку теории человека («понимание», «интуиция», «герменевтика», «описательная и объяснительная психология», «структурный анализ» и пр.) и проблемно-предметные - характеризующие специфику направления или движения как терапию, анализ, психологию («экзистенциальная аналитика», «экзистенциальный анализ», «экзистенциальная психология», «логотерапия» и пр.).

Основание теории экзистенциально-феноменологической психиатрии - онтологические и антропологические концепты. Они наименее устойчивы и в большей мере характеризуют специфику авторских вариантов различных теорий, причем специфичны как содержательно, так и понятийно. Первая группа - это, как правило, заимствованные понятия, приобретшие новое содержание. Это понятия «бытие-вмире», «бытие-за-пределами-мира», «бытие-с-другими», «время», «Dasein», «историчность», «настроенность», «пространственность» «телесность», «темпоральность» и пр. Вторая - понятия в основном новые для экзистенциально-феноменологической традиции, так называемые промежуточные, метаонтические концепты, которые являются узлами философской, әкзистенциальной теории кризиса, лежащей в основании практической составляющей. Это такие концепты, как «проживаемое время» «порядок существования», «экзистенциальное рождение», «априори», «генераторы расстройства» и пр.

Антропологические концепты часто имеют психологическую направленность. Точно так же, как онтологические не являются однозначно онтологическими, а тяготеют к антропологизации, поскольку экзистенциально-феноменологическая традиция на практике нацелена на человека, антропологические концепты психологизированы, поскольку призваны выступить теоретическим основанием практической работы с ним. Это такие понятия, как «воплощенность», «деперсонализация», «болезненный дуализм», «онтологическая защищенность», «не-существование», «самоактуализация», «разрыв», «ужас», «экстравагантность», «ложное Я» и пр.

Большое значение для экзистенциальной традиции на практике имеют коммуникативные концепты. Причем, как правило, они двунаправлены: описывают реальность как врача (практика), так и пациента (клиента). Это «контакт с реальностью», «коммуникация», «открытость», «интенциональное отношение», «со-бытие», «сосуществование», «принятие», «конгруэнтность» и пр. Они наиболее эклектичны в том плане, 
что могут быть связаны с другими концептуальными рядами, приобретая онтологический, методологический, антропологически-психологический оттенок.

Коммуникативные концепты выступают основанием практики экзистенциальнофеноменологической психотерапии и психологии, методологические очерчивают метод работы на уровне теоретической интерпретации, онтологические и антропологические дают для этой интерпретации терминологию и отправные точки. Все они образуют основание синтеза теории и практики.

\section{ЗАКАЮЧЕНИЕ}

Концептуальный анализ, в отличие от простой работы по вычленению понятий, лучше показывает линии преемственности, а также основания этой преемственности. За каждым из концептов - своя предметная реальность. Онтологические отсылают к методологическим, а те к антропологическим, часто возвращающимся вновь к онтологическим. Треугольники, ромбы и множественные переплетения разветвляются и составляют сеть, в которой пациент и терапевт, клиент и психолог отыскивают выход из трудной жизненной ситуации. Концепты в этом случае - метки пути, и в каждом конкретном случае их по-разному можно наносить на карту исцеления, сохраняя или ломая обязательные элементы.

\section{СПИСОК АИТЕРАТУРЫ}

Бинсвангер, $\Lambda$. (2001) Экзистенциально-аналитическая школа мысли // Экзистенциальная психология. Экзистенция / пер. М. Занадворнова, Ю. Овчинниковой. М. : Эксмо. 624 с. С. 308-332.

Власова, О. А. (2014) Антипсихиатрия: Социальная теория и социальная практика. М. : Изд. дом ВШЭ. 430 с.

Власова, О. А. (2010) Феноменологическая психиатрия и экзистенциальный анализ: История, мыслители, проблемы. М. : Территория будущего. 638 с.

Захави, А. (2017) Трансцендентальная феноменология, интенциональность и субъективность // Вопросы философии. № 10. С. 150-155.

Нидлман, Аж. (1999) Критическое введение в экзистенциальный психоанализ $\Lambda$. Бинсвангера // Бинсвангер, $\Lambda$. Бытие-в-мире. М. ; СПб. : КСП+ ; Ювента. 300 с. С. 17-132.

Ясперс, К. (1997) Общая психопатология. М. : Практика. 1053 с.

Binswanger, L. (1963) Existential Analysis and Psychotherapy // Progress in Psychotherapy. Eds. E. M. Reichmann, J. L. Moreno. N. Y. : Basic Books. 360 p. P. 144-168.

Cox, G. (2008) The Sartre Dictionary. L. ; N. Y. : Continuum. 232 p.

Dahlstrom, D. O. (2013) The Heidegger Dictionary. N. Y. : Bloomsbury. 312 p.

Deurzen, E. van, Kenward, R. (2005) Dictionary of Existential Psychotherapy and Counselling. London: Sage Publications. 228 p.

Drummond, J. J. (2008) Historical dictionary of Husserl's Philosophy. Lanham, Md. : Scarecrow Press. 259 p.

Fulford, K. W. M. (1996) Introduction: Just Getting Started // Philosophy, Psychology and Psychiatry. Ed. A. P. Griffiths. Cambridge : Cambridge University Press. P. 1-4.

Gebsattel, V. E., von. (1959) Medizinische Anthropologie. Einführende Gedanken // Jahrbuch für Psychologie, Psychotherapie und Medizinische Anthropologie. № 7. S. 193-198.

Landes, D. A. (2013) The Merleau-Ponty Dictionary. L. ; N. Y. : Bloomsbury. 269 p.

Minkowski, E. (1948) Phénoménologie et analyse existentielle en psychopathologie// L'Évolution psychiatrique. Vol. xiii. № 4. P. 137-185.

Moran, D. (2012) The Husserl Dictionary. L. ; N. Y.: Continuum. 357 p. 


\section{CONCEPTUAL ANALYSIS OF THE EXISTENTIAL AND PHENOMENOLOGICAL TRADITION: FOUNDATIONS AND PERSPECTIVES \\ O. A. Vlasova, A. A. LVOV \\ SaINT-Petersburg State UnIVERSITY}

The paper proposes a novel interpretation of the existential and phenomenological tradition as a joint problematic and applied field at the border of philosophy, psychiatry, psychotherapy, and psychology. It proposes to utilise conceptual analysis as the basis of the study of the conceptual and phenomenological tradition. Such an analysis makes it possible to distinguish the fundamental concepts of the tradition, which remain the same when theory turns into practice or transform into intermediary concepts with the aim of implementing the tasks of therapy.

The authors restore the history of the development of the existential and phenomenological tradition as changing four paradigms: the general one of the humanities, existential and phenomenological, social and critical, and the interdisciplinary paradigm of the philosophy of psychiatry. It is shown that the existential and phenomenological tradition has a fundamental meaning in the light of this process.

The following ranges of concepts of existential and phenomenological philosophy, psychology, psychiatry, and psychotherapy are defined: ontological, methodological, anthropological, and communicative; the status of each conceptual group is clarified. It is pointed out that methodological concepts (those of phenomenology, hermeneutics, and subject-matter) are the conceptual core of the tradition, and they are the most sustainable during the transition from the philosophical to applied field. Ontological and anthropological concepts form the theory and demonstrate the specifics of the authorial projects. They could be both borrowed concepts from philosophy, and authorial metaontical concepts, which are specific to the applied field of the existential and phenomenological tradition and appear at the juxtaposition of philosophical ontology and psychiatric, psychological, and psychotherapeutic anthropology. Communicative concepts are usually connected with other types of concepts and are more eclectic; at the same time, they describe the reality of both the doctor, and the patient.

The paper observes the prospects of the introduced interpretative model, in which the foundations and outlines of methodological and theoretical continuity in the framework of various fields of tradition are clarified.

Keywords: existential and phenomenological tradition; phenomenology; existential philosophy; conceptual analysis

\section{REFERENCES}

Binswanger, L. (1960) Existential Analytic School of Thought. Existence: A New Dimension in Psychiatry and Psychology. Eds. R. May, E. Angel, H. F. Elllenberger. New York, Basic Books, pp. 191?212.

Vlasova, O. A. (2014) Antipsikbiatriia: Sotsial' naia teoriia i sotsial' naia praktika. Moscow, Izd. dom VShE. 430 p. (In Russ.)

Vlasova, O. A. (2010) Fenomenologicheskaia psikbiatriia i ekzistentsial'nyi analiz: Istoriia, mysliteli, problemy. Moscow, Territoriia budushchego Publ. 638 p. (In Russ.)

Zakhavi, D. (2017) Transtsendental'naia fenomenologiia, intentsional'nost' i sub»ektivnost'. Voprosy filosofii, vol. 10, pp. 150 ? 155 . (In Russ.)

Needleman, J. (1967) A Critical Introduction to Ludwig Binswanger's Existential Psychoanalysis. Being-in-the-World: Selected Papers of Ludwig Binswanger. Ed. J. Needleman. New York, Harper Torchbook, pp. 7?145.

Iaspers, K. (1997) General Psychopathology. New York, JHU Press. 922 p.

Cox, G. (2008) The Sartre Dictionary. London; New York, Continuum. 232 p.

Dahlstrom, D. O. (2013) The Heidegger Dictionary. New York: Bloomsbury. 312 p.

Deurzen, E., van, Kenward, R. (2005) Dictionary of Existential Psychotberapy and Counselling. London, Sage Publications. 228 p. 
Drummond, J. J. (2008) Historical dictionary of Husserl's philosopby. Lanham, Md., Scarecrow Press. 259 p.

Fulford, K. W. M. (1996) Introduction: Just Getting Started. Philosopby, Psychology and Psychiatry. Ed. A. P. Griffiths. Cambridge, Cambridge University Press, pp. 1-4.

Gebsattel, V. E., von. (1959) Medizinische Anthropologie. Einführende Gedanken. Jabrbuch für Psychologie, Psychotherapie und Medizinische Antbropologie, 1959, no. 7, S. 193-198.

Landes, D. A. (2013) The Merleau-Ponty Dictionary. London; New York, Bloomsbury. 269 p.

Minkowski, E. (1948) Phénoménologie et analyse existentielle en psychopathologie. L'Évolution psychiatrique, 1948, vol. xiii, no 4, pp. 137-185.

Moran, D. (2012) The Husserl Dictionary. London; New York, Continuum. 357 p.

Submission date: 12.11.2017.

Власова Ольга Александровна - доктор философских наук, доцент, профессор кафедры истории философии Санкт-Петербургского государственного университета. Адрес: 199034, Россия, г. Санкт-Петербург, Менделеевская линия, д. 5. Тел.: +7 (812) 328-94-21, доб. 1841. Эл. aдpec: o.a.vlasova@gmail.com

Цьвов Александр Александрович - кандидат философских наук, старший преподаватель кафедры онтологии и теории познания Санкт-Петербургского государственного университета. Aдрес: 199034, Россия, г. Санкт-Петербург, Менделеевская линия, д. 5. Тел.: +7 (812) 328-94-21, доб.1845.Эл. адрес: a.lvov@spbu.ru

Vlasova Olga Aleksandrovna, Doctor of Philosophy, Associate Professor, Professor, Department of History of Philosophy, Saint-Petersburg State University. Postal address: 5, Mendeleev Line, SaintPetersburg, Russian Federation, 199034. Tel.: +7 (812) 328-94-21, ext.: 1841. E-mail: o.a.vlasova@gmail.com

Lvov Aleksandr Aleksandrovich, Candidate of Philosophy, Senior Lecturer, Department of Ontology and Theory of Knowledge, Saint-Petersburg State University. Postal address: 5, Mendeleev Line, Saint-Petersburg, Russian Federation, 199034. Tel.: +7 (812) 328-94-21, ext.: 1845. E-mail: a.lvov@spbu.ru 